\title{
The Application Research of Game Theory in the Administrative Power and the Academic Power
}

\author{
Jiao $\mathrm{LI}^{1, \mathrm{a}}$ \\ ${ }^{1}$ Hua Xia College of Wuhan University of Technology, Wuhan, Hubei, China \\ a13600496@qq.com
}

Key words: Higher education, Administrative power, Academic power, Game theory, Fusion, Check and balance.

\begin{abstract}
Based on the analysis of the game between the administrative power and the academic power, Using game analysis tree configuratates the college administration reasonably. And based on this, the modes of the fusions, checks and balances are given between the administrative power and the academic power.
\end{abstract}

\section{Introduction}

The game theory was originated from the research by Gounod in 1983. In the 1950s, game theory obtained real development, and concern of the people all over the world through the concept of "Nash equilibrium". Game theory studies the decisions and equilibrium of the decision-making body whose behaviors are interacted directly, including the rational behavior of mutual interdependence situation. The standard game structure includes three basic elements: the players, the strategy each player can choose, and payoff function. Collectively, the players, actions and results are called "rules of the game". The game is classified into several types: a single game, double game and multiplayer game, mainly according to the number of parties; regular game and variable game according to income structure; divided into static game, dynamic game and repeat game according to the order of game; complete information game and the incomplete information game according to the information state; cooperative game and non-cooperative game according to the starting point of players' behavior. [1]

Administrative power and academic power of our colleges and universities are mutually penetrated and balanced. In this system, there arouse several problems like over-broad administrative powers, the relative weakening academic power, weak participation of professor in school affairs. For solving problems above, this article uses game theory to perform reasonable configuration of the university's administrative power and academic power, in order to make the two collaborate with each other to promote the harmonious and stable development of colleges and universities.

\section{The academic power and administrative power in college and their dialectical relationship}

University academic power refers to the rights of managing school-related academic activities possessed by the academic committee which is composed of school experts, professors, scholars. The academic power has characteristics like highly specialized, relatively liberal environment; persist in the democratic majority rules, the emphasis on academic freedom. Academic power is mainly exercised by experts and scholars through their own academic influence and appeal.

The administrative power of the university is an institutionalized right, which is mandatory to manage the university administrative members based on national laws and school regulations, in order to enable universities to be normally and orderly operated, and achieve the goals pursued by the universities. The college administrative power has the characteristics of institutionalized, mandatory, hierarchy, and level of obedience. Such administrative power also reflects the will of the state and government, social demands and the needs of the people. 
The dialectical relationship between academic power and administrative power in college [2][3][4]

\section{Unity}

The main duties of the university is imparting knowledge, teaching and educating people, in which process, college teachers who have a wealth of knowledge and high level of scientific research establish a mutual relationship of teaching and learning with the students who have the urgent need to learn knowledge. Thus, University teachers and their academic organizations constitute the main body of the academic power, which, however, requires administrative power to support in the decision-making process of the academic matters, in the maintenance of order, in the configuration of the human, financial and other resources, as well as the normal teaching and research activities. Meanwhile, as the target of the administrative power, the better development of teaching and research is also conducive to the implement of administrative power, because many administrative are professors or experts in some fields. The top-down hierarchical organization of administrative power, by virtue of a clear division of labor and the level, completes the school administrative work, make systematic and environmental assurance for academic activities of experts and professors and deliver good service. Overly speaking, administrative power and academic power in the colleges are mutually interdependent, reinforced, integrated, indivisible, and uniformed.

\section{Independence}

The university's administrative power and academic power are relatively independent. Colleges in China carry out "the president responsibility under the leadership of party committees system". The administrative power of the secretary and presidents is appointed by the organization file, and is exercised to manage the school from top to bottom through a series of rules and files. The academic power mainly relies on the academic charm or the academic status of the experts or scholars and academic organizations to exercise the academic power like to participate in the school's teaching and research, and the formulation of academic principles and policies, etc. Academic powers emphasizes on democracy and equality. Administrative power and academic power are like two lines in university management, play a decisive role outside and dominant role inside respectively for the university development goals.

\section{Shortcomings and contradictions of academic and administrative power}

For the administrative power, (1) the administerization and institutionalization of administrative power easily lead to the idea of "official position", the bureaucracy and formalism; (2) administrative power only works in a specific time and space, towards a particular object within a specific range of works, so it has some limitations. For academic power, (1) academic power is exercised by some experts or their academic organization in some fields, so they are more concerned about personal improvement of academic standards and the development of their disciplines. It is difficult to take into account the interests of the whole; (2) rules of academic power in the decision-making process, like democracy and equality, academic freedom and the principle of the subordination of the minority to the majority, is likely to cause loose, disorder status, making the decision-making process inefficient and difficult to determine, and thus missing the opportunity.

The contradiction between academic and administrative power lies in: (1) administrative power stresses absolute obedience, while academic power emphasizes academic freedom; (2) the strengthening of the administrative power and weakening of the academic power make the administrative powers beyond their own boundaries, too much interference to the free development of academic power; (3) there was a contradiction between the resource needed by experts and professors in teaching and research and resource allocated by administrative departments. 


\section{The application of game theory in reasonable allocation of academic power and administrative power}

\section{Nash equilibrium and Pareto efficiency}

Nash equilibrium, named after Nobel Prize winner John Nash. The main idea: suppose there are $\mathrm{n}$ players involved in the game. Given the conditions of other people's strategy, each player chooses the optimal strategy (personal optimal strategy may depend on to may not rely on others' strategy), thereby maximizing their own interests. All the players' strategies constitute a strategy combination consisting of the optimal strategy by all participants. In the case given others' strategy, no one have enough reason to break this equilibrium. Nash equilibrium, in essence, is a non-cooperative game state. [5]

Pareto efficiency, also known as the Pareto optimal, Pareto improvement, Pareto optimal configuration, is named after the Italian economist Vilfredo Pareto. He is the earliest to use this concept in the research on economic efficiency and the distribution of income. Pareto optimal refers to an ideal state of the resource allocation, i.e. Given an initial allocation of goods among a set of individuals, a change to a different allocation that does not make any individual worse off can not make any other individual better off. In other words, it is no longer possible to improve the situation of some people without causing any damage to other people. [6]

\section{The reasonable configuration between academic power and administrative power}

Nowadays, the problems like generalization of administrative power in the colleges or universities, or the lack and dislocation of academic power, all have a tremendous impact on the development and training of qualified person in the university. Therefore, it is urgent to find a balance in the game between the administrative power and academic power, leading the two working on each line, and making a positive contribution to the leaps and bounds of universities.

Concerning with the university's administrative power and academic power, we can not just use a simple digital formula to describe it. This article uses the decision tree in the game theory to make analysis, as shown in 1.

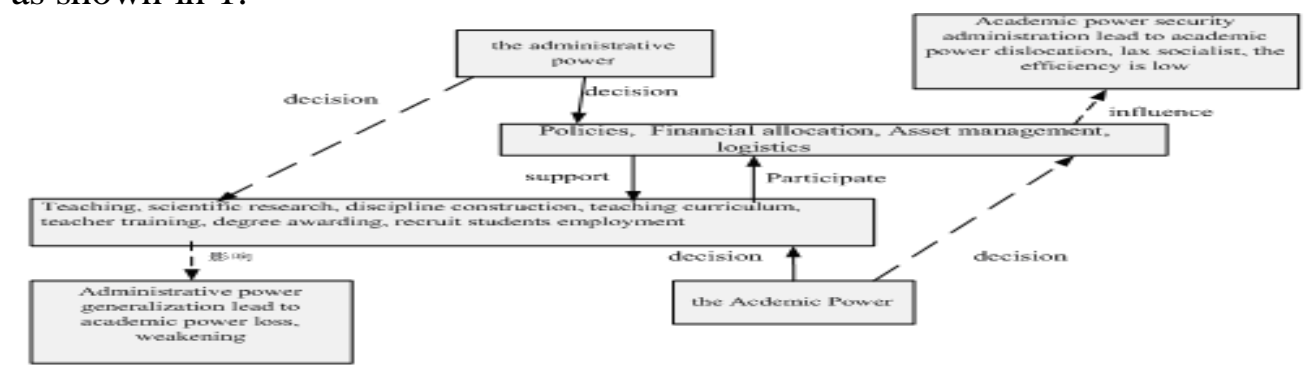

Figure 1 Game decision tree of administrative power and academic power in college affairs

Through the game decision tree, we can clearly get the relationship between administrative power and academic power in various affairs of colleges or universities. Administrative power maintains normal school teaching and scientific research according to the formulated regulations of the school based on the government's principles and policies. Administrative power makes reasonable distribution of school property to ensure the rational use of the normal teaching and scientific research funds, sites, and related instrument. Academic power is mainly to provide free and relaxed academic environment for the school teaching and scientific research, to provide academic support for the establishment of the subject and the construction of related courses, to train teachers, to provide decision for the academic committee to award the degree as well as the corresponding advice to the recruitment and employment of students. If administrative power intervenes in the teaching and scientific research, discipline construction, teacher training, degree awarding, the academic content, it is likely to cause the generalization of administrative power, loss and weakening of academic power. If academic power intervenes too much in the policies of the school 
system, such as the formulation of rules, the distribution and management of financial assets, logistics, it is easy to cause the administerization of academic power, academic dislocation, lax socialist, low work efficiency. Therefore, it can be seen that in universities, administrative power is mainly to provide support and guarantee the normal operation of academic power; academic power can participate in administrative power, but cannot control administrative power. As a result, we should build limited academic power and service administrative power in colleges. If the administrative power and academic power play positive roles within their respective scope, the overall interests of the college will rise, and we can achieve Nash equilibrium.

We use a simple example to give a more specific and vivid description of the game relationship between the administrative power and academic power. If the two kinds of power can cooperate well with each other and fulfill their own jobs, we use [10, 10] to signify, the former number meaning satisfaction or profit of administrative power, the latter meaning the satisfaction or profit of the academic power. We use [11,6] to say broadening administrative power and weakening academic power, and [6,11] to mean administerization of academic power. Relative to [10, 10], although [11] and $[6,11]$ have a party of larger interests, but the larger profit is from the reduced interests of the other party, causing the other party is unwilling to cooperate in the work, so we consider $[10,10]$ to achieve the Pareto Optimal Efficiency.

\section{The game and blending of administrative and academic power}

Administrative power in universities consists of school leaders, ranking leaders (middle-level cadres), middle-level officials and management staff as shown in figure 2.

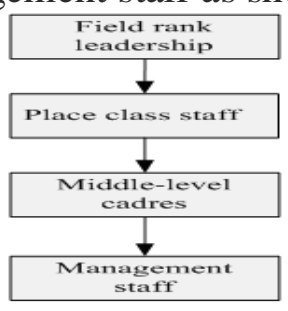

Figure2 the structure of administrative power

Its working method is to convey and implement from top-down the school administrative demands of rules and regulations, decision and various aspects of the management based on the requirements of government by holding meetings. The whole process is mandatory.

The structure of academic power is shown in figure 3.

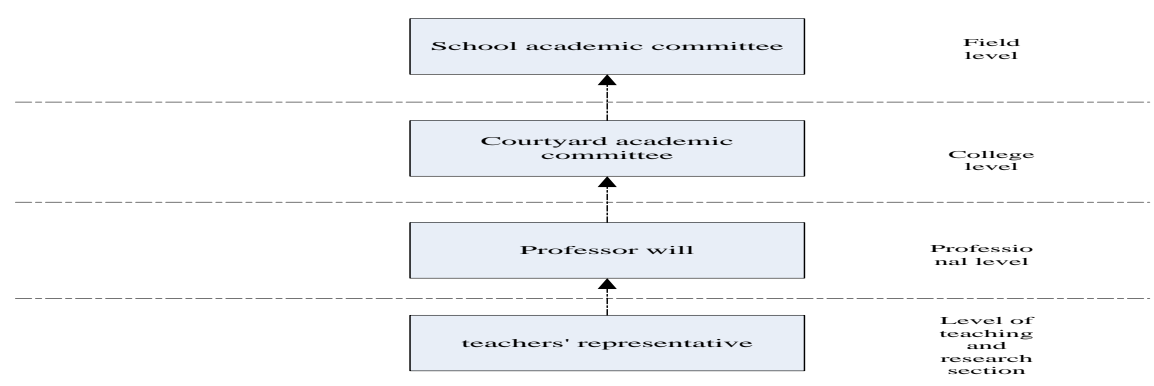

Figure 3 the structure of academic power

At the level of school, there are school academic committee, whose main body is composed of high-level professional and technical experts and scholars in various fields. In department, it is academic committee of department, which is mainly composed by high-level experts or scholars and professors with a senior professional title. Each major has its own professional committee composed of experts and professors. All teaching and research section have their representative 
teachers. In the whole process, academic power is delivered to the lower level as far as possible, with the lower layer responsible for the upper layer. [8]

The administrative power and academic power in colleges and universities are mutually infiltrated and contradicted, but also mutually restricted and balanced. In the process of the game, it is vital to harmonize the relationship between administrative power and academic power, promoting the development of the college harmony and stability. This paper argues that the administrative power and academic power should establish the following relation of mutual fusion and balance as shown in figure 4.

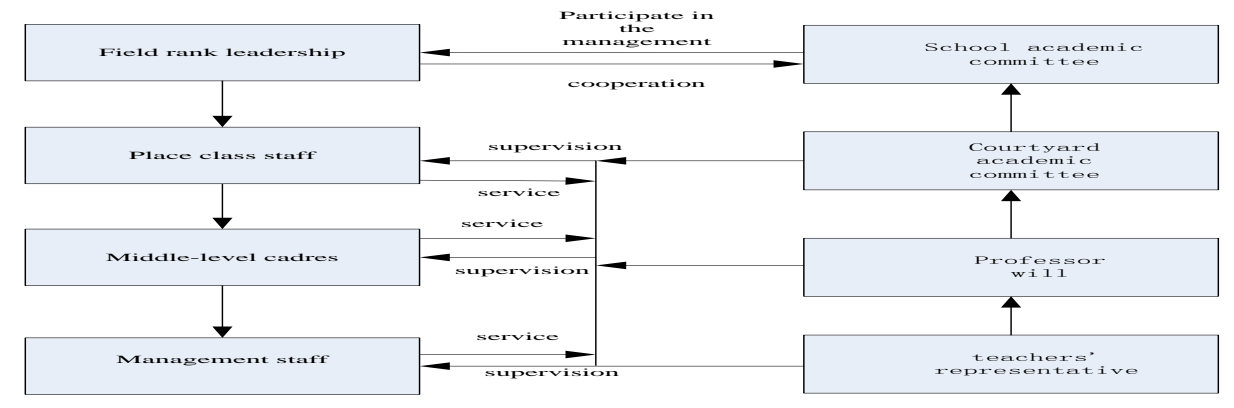

Figure4 the fusion of administrative and academic power in colleges

In the system of academic power as in the figure, teachers in teaching sections, professors and academic committee conduct supervision to the middle-level cadres, middle-level officials, and management personnel, reflect the results of supervision to academic committee in the school. The school academic committee participates in the management of daily affairs and the formulation of relevant system. For the problems reflected by academic organization at all levels, school academic committee can directly supervise and manage. The decisions made by the school leaders should be approved by the school academic committee to be carried out, thus increasing the power of the academic committee to participate in school management. In this system, presidents in the colleges or universities should play the role of coordination between the two, because the presidents are not only the school leaders, but also the school committee members. The coordination effect of the principal makes the administrative power and academic power obtain a very good fusion, so as to ensure the coordination and consistency in the process of work cohesion.

\section{Summary}

Based on a dialectical analysis of administrative power and academic power, this paper uses game analysis tree in the game theory to make reasonable configuration of work contents in the two rights. Besides, by analyzing the structure of administrative power and academic power, this paper gives a game management mode of administrative power and academic power mutually combined, checked and balanced, in order to improve the status and role of academic power in university management.

\section{References}

[1] Yao guoqing. Game theory [M].Tian jing: Nankai university press,2003.10.

[2] Zhang xiaoli. The administrative power and academic power in research [J]. Academic communication, 2006 (10).

[3]Ren weizhen. University academic power and administrative power coordination [J]. Ningxia social science, 2006 (6).

[4] Li xiaolong. Analyses the internal academic power and administrative power relationship [J]. The contemporary education, 2008 (11). 
[5] Baidu: http://www.baidu.com/.

[6] Wang chunyong. Game theory trick: daily life game strategy [M]. Beijing:China's development press,2007.10.

[7] Wu Jian. In the management of university academic power and administrative power coordination $[\mathrm{J}]$. Higher education research, 2005 (8).

[8] Cao Weixing, Zhao Yuemin, Gao Chi. Improve the academic power to explore Chinese characteristics professor guide mode [J]. China's higher education, 2004 (1). 